\begin{tabular}{ll}
\hline 著 \\
\hline
\end{tabular}

\title{
頭蓋内内頚動脈前壁動脈瘁の臨床的検討
}

\author{
竹下 幹彦, 恩田 英明, 谷川 達也 \\ 井沢 正博，加川 瑞夫，高倉 公朋
}

\section{Clinical Analysis of the Aneurysms of the Anterior Wall of the Intracranial Internal Carotid Artery}

\author{
Mikihiko Takeshita, M.D., Hideaki Onda, M.D., Tatsuya Tanikawa, M.D., \\ Masahiro Izawa, M.D., Mizuo Kagawa, M.D., and Kintomo Takakura, M.D. \\ Department of Neurosurgery, Neurological Institute, Tokyo Women's \\ Medical College, Tokyo, Japan
}

Summary: We investigated clinical characteristics and operative results in 7 patients with aneurysm arising from the anterior (dorsal) wall of the intracranial internal carotid artery. They were 1 male and 6 females and their ages ranged from 27 to 69 . Six of the 7 patients presented subarachnoid hemorrhage of various clinical grades, while an aneurysm was found incidentally in 1 patient. Angiography showed a saccular aneurysm in 3 cases, but demonstrated only a little protrusion from the arterial wall (semifusiform type) in 4 cases, of which 1 required a repeated angiography for the exact diagnosis. Two patients had a coexisting unruptured aneurysm on the same side. Five patients underwent clipping operation within 2 days of hemorrhage. Operative findings disclosed not only a fragile aneurysmal neck in every patient but also thinning of the arterial wall itself in some patients. The aneurysmal clip was principally applied parallel to the internal carotid artery, including the normal arterial wall, and the arterio-aneurysmal complex was totally wrapped with the Bemsheet or muscle fascia. The aneurysm was completely obliterated by a single clipping procedure in 4 patients including 1 with unruptured aneurysm. One patient showed regrowth of aneurysm at the superior-medial portion of the clipped aneurysm on the day after the first operation, and presented recurrent hemorrhage from enlarged aneurysm 14 days later. In a second operation, because of a large laceration at the aneurysmal neck, an angioplasty by suturing the remaining arterial wall was required. Premature rupture was also encountered in 2 other patients. Although hemostasis was accomplished by re-clipping procedure in 1 of the 2 patients, the other patient required arterial suture for angioplasty. The outcomes of 2 patients with angioplasty were extremely poor.

Based on these results, aneurysms of the anterior wall of the intracranial internal carotid artery (IC) should be definitely distinguished from the other aneurysms, since they show outstanding clinical characteristics such as a rapid growth or regrowth within short periods, a vulnerable neck liable to rupture and a broad neck difficult to be repaired when lacerated.

Although most IC anterior wall aneurysms may be successfully clipped by applying the clip blade parallel to the parent artery, the arterial wall around the aneurysm should be completely wrapped to prevent the aneurysmal regrowth. When the aneurysmal neck is too broad to reconstruct the arterial wall by clipping, trapping of aneurysm with a high flow shunt is recommended.

東京女子医科大学 脳神経センター 脳神経外科（受稿日 1996. 8.7)〔連絡先：テ162 新宿区河田町 8-1 東京女子医科大学 脳神経セン 夕ー 脳神経外科 竹下幹彦〕〔Mailing address: Mikihiko TAKESHITA, M.D., Department of Neurosurgery, Neurological Institute, Tokyo Women's Medical College, 8-1 Kawada-cho, Shinjuku-ku, Tokyo 162, Japan]

\author{
Key words: \\ - dorsal aneurysm \\ - aneurysm of the \\ superior wall \\ - internal carotid \\ aneurysm \\ - clipping \\ - surgical treatment
}

Surg Cereb Stroke (Jpn) 25: 134-139, 1997 
はじめに

頭蓋内内頸動脈前壁動脈瘤は, $\mathrm{C} 1, \mathrm{C} 2$ 部の内頸動脈瘤 のうち眼動脈, 後交通動脈や前脈絡叢動脈などの分岐血管 と関係なく生じる動脈瘤で，その多くは前上方に発育し明 瞭な動脈瘤頸部をもたない。本動脈瘤壁は脆弱であり, 破 裂の危険性が高く，術中動脈瘤の処置に困難を伴うことも 多い。過去の報告では, このような動脈瘤は“dorsal internal carotid artery aneurysm”4)8)または “dorsal type” と呼ばれ，動脈瘤が小さい場合 “blood blister like”と表 現されている10).

今回われわれは, 当センターで経験した本動脈瘤 7例に ついて，血管撮影所見および臨床上の特徴からその本態お よび治療上の問題点について検討したので報告する.

\section{対象および方法}

対象は，1990年から 1995年にわたる過去5年間に当セ ンターにおいて外科的処置を行った内頸動脈前壁動脈瘤の 7 例で, 年齢は $27 \sim 69$ 歳(平均 51.7 歳)である.この 7 例に ついて, 術前重症度 (Hunt \& Kosnik grade) などの臨床症 状, 脳血管撮影所見, 動脈瘤の増大 - 再発, 術中所見およ び転帰などについて検討した。

\section{結果}

7 例の男女比では, 男性 1 例, 女性 6 例で女性に圧倒的 に多く, 動脈瘤の部位では左側 5 例，右側 2 例であった。 臨床症状では 6 例がクモ膜下出血で発症し, 他 1 例は incidentalに発見された。脳血管撮影上， 3 例はsaccular な動脈瘤であったが, 他の 4 例では動脈瘤はわずかな隆起 (semifusiforme type) のみで，この 4 例中 2 例に同側の合 併動脈瘤を認めた. 術前重症度はクモ膜下出血で発症した 6 例では, Grade II と Grade IIIが各2例, Grade IV, Vが 各 1 例であり様々な gradeを示した. クモ膜下出血で発症 した 6 症例のうち 5 例ではday 2 以内の急性期に手術を行
った。クモ膜下出血発症後 15 日目に手術を行った例は, 発症日および発症翌日の脳血管撮影では本動脈瘤と明瞭に 判断できず，発症 2 週間目の脳血管撮影にて明暸な本動脈 瘤を認めた症例である(Table 1). 手術所見では, 全例で動 脈瘤自体と頸部付近の動脈壁の脆弱性を認めた. clipping 操作では，動脈壁の脆弱な部分を残さないようにclipの blade と内頸動脈(IC)の走行ができるかぎり parallelになる ようにapplyした. 1 回の clipping操作で動脈瘤を処置で きたのは 4 例で, 術後血管撮影でも clip 周囲に新たな動脈 瘤の発生は認めず転帰は良好であった。一方 3 例で術中破 裂を認め，1例では動脈瘤の clippingにて止血が可能であ ったが，他 2 例では内頸動脈の縫合による血管形成が行わ れた。また，全例に動脈瘤周囲に筋肉片やBemsheet等を 用いる何らかの wrappingを必要とした。術後の転帰は， 内頸動脈の血管形成を行った 2 例は不良であったが，他の 5例は良好であった。

\section{症例呈示}

$<$ Case $7>57$ 歳, 男性.

突然の頭痛, 意識障害を主訴として来院した. 意識はI2 (JCS) で項部硬直を認めたが神経脱落症状は認めなかっ た。頭部単純CTにて脳底槽にdiffuseなクモ膜下出血を認 めた. 左内頸動脈撮影では, 内頸動脈 $(\mathrm{C} 1)$ の前上方に突出 する semifusiform状の動脈瘤 (矢頭) と内頸動脈の cavernous portionで前方に向く saccularな動脈瘤を認めた (Fig. 1A). クモ膜下出血の原因を C1 の semifusiform状の 動脈瘤と考え day 1, Grade I (Hunt \& Kosnik)にて本動脈 瘤に対し前頭側頭開頭を行った。術中所見では，脳底槽に 中等度のクモ膜下出血と内頸動脈の C1 部に後交通動脈よ り近位部で頸部の広い動脈瘤とその付近の動脈壁の脆弱性 を認めた．動脈壁の脆弱な部分をできるだけ残さず動脈瘤 を curved clip を用いて clippingし，周囲を muscleでwrappingした。術翌日の左内頸動脈撮影(Fig. 1B)では, 動脈瘤 clipの内側に動脈瘤の一部が造影されたが(矢印), 術後の

\section{Table 1}

\begin{tabular}{|c|c|c|c|c|c|c|c|c|}
\hline $\begin{array}{l}\text { Case } \\
\text { No. }\end{array}$ & $\begin{array}{l}\text { Age (yrs) } \\
\text { sex }\end{array}$ & $\begin{array}{l}\text { Preoperative } \\
\text { Grade }\end{array}$ & $\begin{array}{l}\text { Side of } \\
\text { aneurysm }\end{array}$ & $\begin{array}{l}\text { Interval from } \\
\text { SAH } \\
\text { to operation }\end{array}$ & $\begin{array}{l}\text { Shape of } \\
\text { aneurysm }\end{array}$ & $\begin{array}{l}\text { Intraoperative } \\
\text { rupture }\end{array}$ & $\begin{array}{c}\text { Aneurysm } \\
\text { management }\end{array}$ & Results \\
\hline 1 & 69 , female & IV & right & 1 day & semifusiform & yes & clipping + wrapping & good \\
\hline 2 & 45 , female & III & left & 2 days & saccular & no & clipping + wrapping & excellent \\
\hline 3 & 45 , female & 0 & left & - & saccular & no & wrapping & excellent \\
\hline 4 & 55 , female & III & left & 1 day & semifusiform & yes & clipping + wrapping & excellent \\
\hline 5 & 27 , female & II & left & 15 days & saccular & no & clipping + wrapping & excellent \\
\hline 6 & 64 , female & $\mathrm{V}$ & right & 1 day & semifusiform & yes & angioplasty + wrapping & poor \\
\hline \multirow[t]{2}{*}{7} & 57 , male & II & left & 1 day & semifusiform & no & 1st clipping + wrapping & \\
\hline & & & & & & yes & 2nd angioplasty + wrapping & dead \\
\hline
\end{tabular}



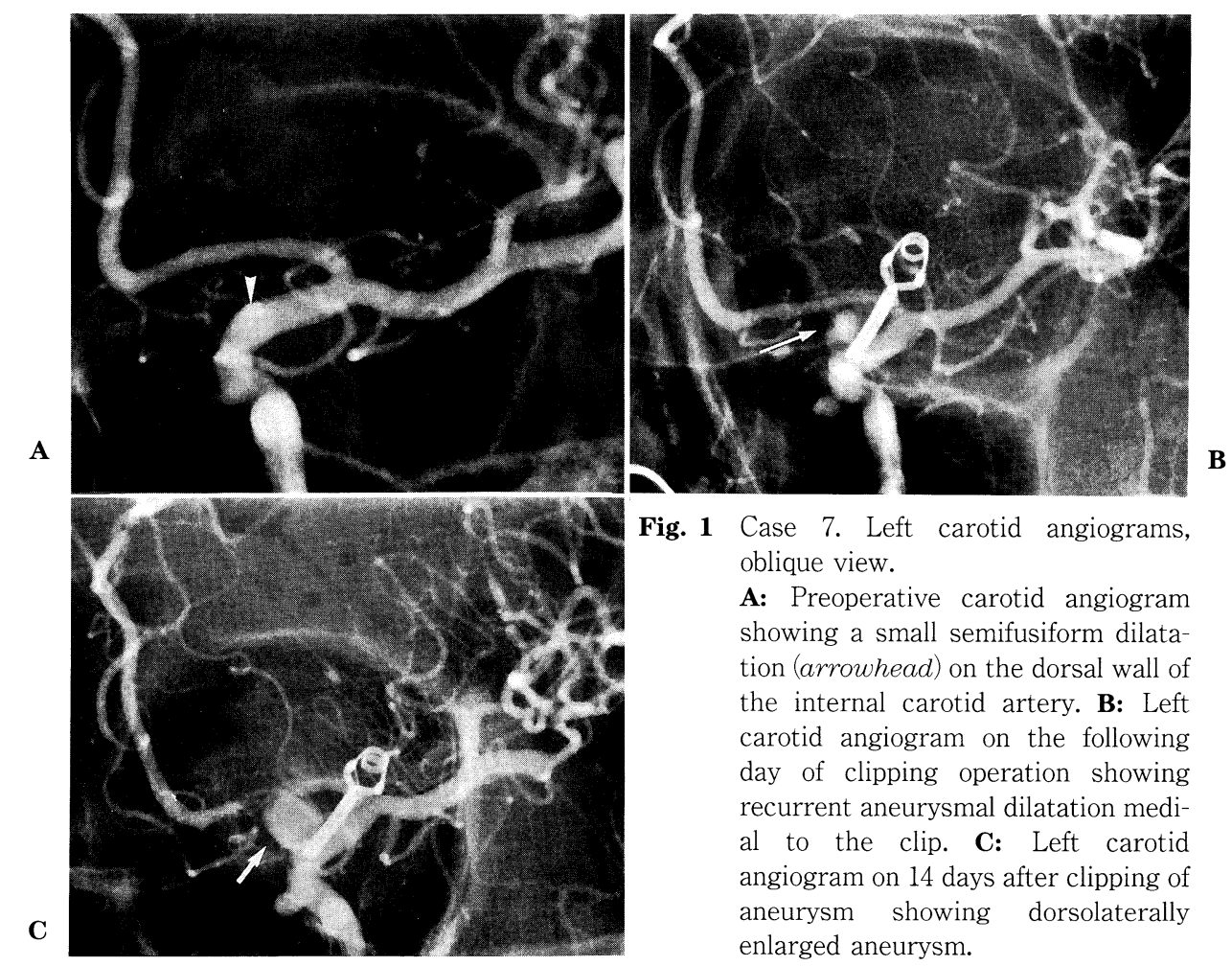

Fig. 1 Case 7. Left carotid angiograms, oblique view.

A: Preoperative carotid angiogram showing a small semifusiform dilatation (arrowhead) on the dorsal wall of the internal carotid artery. B: Left carotid angiogram on the following day of clipping operation showing recurrent aneurysmal dilatation medial to the clip. C: Left carotid angiogram on 14 days after clipping of aneurysm showing dorsolaterally enlarged aneurysm.

意識障害と脳の swellingが強いため, このまま保存的療法 を行った。術後 10 日目には意識 I-3程度まで回復したが, 術後2週間目(day 14)に再度クモ膜下出血を起こし, coma となった。同日行われた左内頸動脈撮影(Fig. 1C)では, 術翌日の血管撮影よりも増大した動脈瘤(矢印)を認めたた め緊急にて手術を行った。まず頸部内頸動脈を確保した後, 前回の皮切を利用して再開頭を行った。動脈瘤頸部の剥離 操作中にneckより出血し, 動脈瘤ごと千切れて内頸動脈 の lacerationのみとなった. laceretionの部分が幅広く, この状態では clipping困難と考え，残存した血管壁を 6-0 Dexonで 3 針縫合し, 内頸動脈の血管形成を行った. 同部 位血管の狭窄を認めたが，ICを一緒に全周にわたって fasciaで wrappingし, その上から内頸動脈に parallel に clippingした. 術後は意識の改善なく 2 週間で死亡した.

\section{$<$ Case 6> 64歳, 女性.}

突然の頭痛とその後の強い意識障害にて来院した。神経 学的には意識III-100 (JCS), 四肢麻痺を認めた。頭部単純 CTにて脳底槽にdiffuseで強いSAHを認めた。右 CAGで は内頸動脈の前上方に突出する小さな semifusiform状の 動脈瘤を認めた(Fig. 2). まず頸部内頸動脈を確保した後, 右前頭側頭開頭を施行した. 術中所見では, 動脈瘤頸部付 近の内頸動脈壁の脆弱性を認めたため, 破裂を裂けるため に“subpial”に剥離操作をすすめた。しかし血腫を取除 いたところでneckより出血し, 動脈瘤ごと千切れて同部 位は内頸動脈の lacerationのみとなった. clipping困難と 考え，正常血管壁を利用して縫合による血管形成を行い， 内頸動脈を全周にわたってduraでwrappingし，その上か ら内頸動脈に parallel clippingした. 術後の右内頸動脈撮 影(Fig. 3)では, 内頸動脈および後交通動脈のpatencyは保 たれていたが，術後意識の改善なく，転帰は不良であった。

\section{$<$ Case 5 > 27歳, 女性.}

突然の激しい頭痛にて発症. 発症時の CTにて脳底槽に diffuseで強いSAHを認めた。同日の左内頸動脈撮影では, 明瞭な動脈瘤を認めず, 翌日左内頸動脈撮影の斜位像 (Fig. 4A)にて，内頸動脈の背側にわずかな膨隆を認めたが, 動脈瘤と判断できなかった. 2 週間後の左内頸動脈撮影で は，内頸動脈の前壁にsaccularな動脈瘤を認めた (Fig. 4B). 術中所見では, 動脈瘤自体とその頸部付近の動脈壁の脆弱 性を認め, 動脈壁の脆弱な部分を残さないよう動脈瘤を clippingし，周囲をcoating して手術を終了した。術後の 左内頸動脈撮影(Fig. 5)でも動脈瘤を認めず, deficitなく 退院した。 


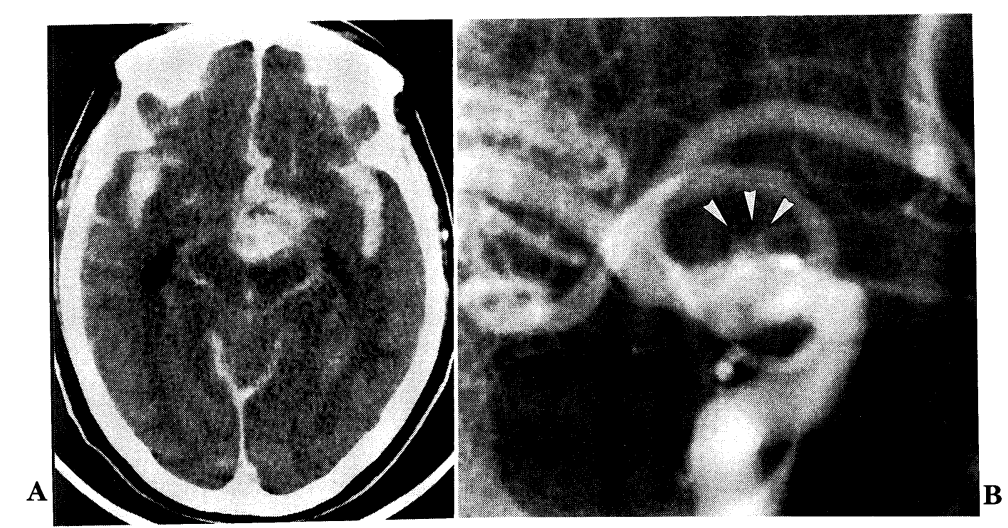

Fig. 2 Case 6. A: CT scan demonstrating diffuse sabarachnoid hemorrhage and thick hematoma in the right basal cisterns. B: Right intenal carotid angiogram of oblique view demonstrating an irregular semifusiform type aneurysm projecting superiorly (arrowhead).

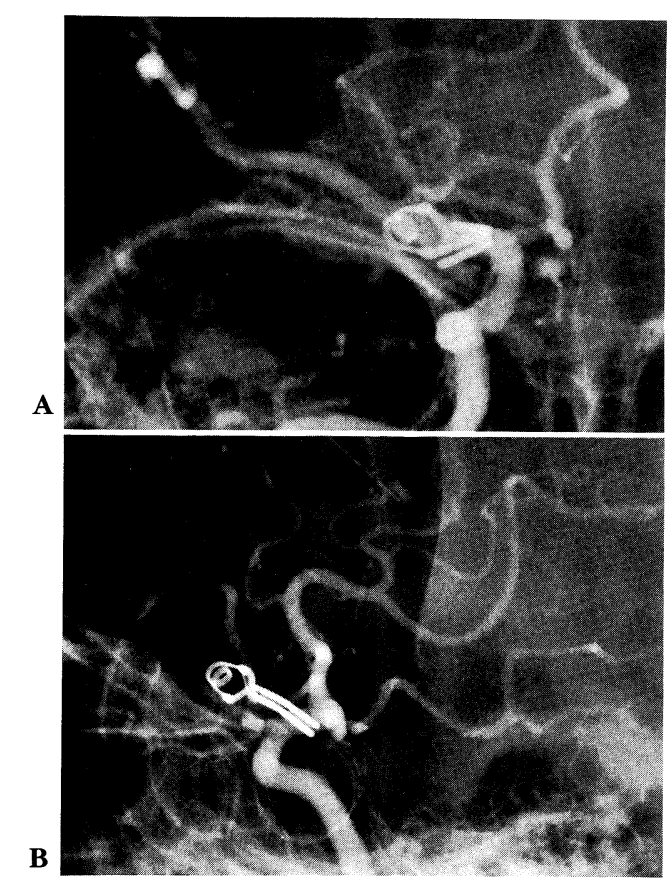

Fig. 3 Case 5. Postoperative right carotid angiogram showing successful angioplasty (A; lateral view, $\mathbf{B}$; anteroposterior view).

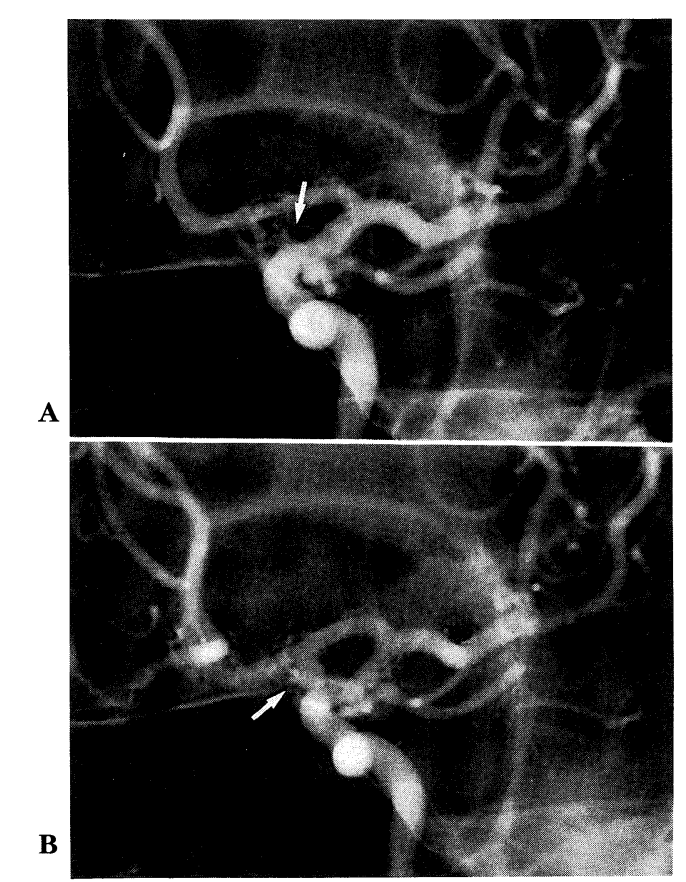

Fig. 4 Left internal carotid angiograms (oblique view). A: Left carotid angiogram on the following day of SAH demonstrating a faint aneurysm projecting dorso-medially (arrow). B: Left carotid angiogram on 14 days after SAH demonstrating an enlargement of the aneurysm (arrow).

\section{考察}

内頸動脈前壁動脈瘤の発生頻度は, 内頸動脈瘤の $0.9 \sim$ $6.5 \%^{7) 11)}$ と報告されており，まれな動脈瘤である。これま でaneurysm of superior wall of internal carotid artery ${ }^{11)}$, IC dorsal wall aneurysm ${ }^{2)}$, blister like aneurysm ${ }^{5) 10)}$, immature berry aneurysm ${ }^{1)}$, ちまめ状動脈瘤 ${ }^{10)}$, 粒状動 脈瘤 ${ }^{6)}$ などと様々な名称で報告されてきたが，これらはい 


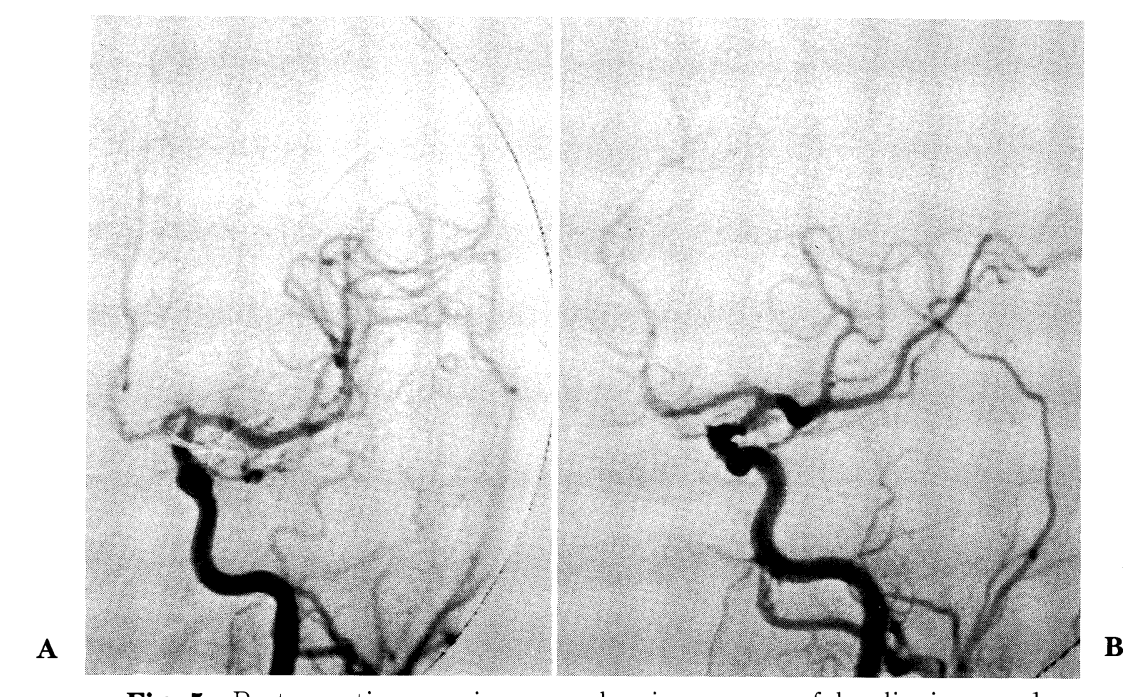

Fig. 5 Postoperative angiogram showing successful clipping and restored blood circulation. (A; AP view, B; lateral view)

ずれも同じ範疇に属すると考えられる。しかし名称につい ては，特に本動脈瘤が “dorsal”と表現されることに解剖 学的見地から異議も唱えられている。われわれは，おもに 解剖的見地から本動脈瘤の名称として aneurysm of the anterior wall of the intracranial internal carotid artery 最も適切であろうと考えている。

内頸動脈前壁動脈瘤の発生原因について言及した報告は 少ないが, 高橋ら ${ }^{10)}$, 岡田ら ${ }^{5)}$ は, 内頸動脈の特異な hemodynamics と動脈硬化がこの特殊な動脈瘤の形成に関 与しているとした。佐藤ら ${ }^{7)}$ は，動脈瘤が若年者に多いこ と，急速な増大が認められること，動脈瘤壁の極端な脆弱 性を示すこと，血管撮影所見で内頸動脈の狭窄や二重陰影 を認めることより, 本動脈瘤の成因について解離性動脈瘤 と推測している。しかし，佐藤ら ${ }^{7)}$ その報告で述べてい るように，すべての前壁動脈瘤が解離性由来とは判断し難 いと述べ, 内頸一眼動脈瘤の subchiasmal typeの一部のも のに血管分岐とは関係なく背内側に突出するものがあり, これが背側 (前壁) 型動脈瘤の分類の中に入っている可能性 を示した．解離性動脈瘤との説をとると，われわれが，し ばしば経験する椎骨動脈解離性動脈瘤とは壁内血栓の有無 など術中所見が異なることもまた事実である。

この内頸動脈前壁動脈瘤が，様々な名称で呼ばれ他の内 頸動脈瘤と異なる範疇で報告される理由は, きわめて特徴 的な臨床症状を有していることにある．最も注目すべき特 徵としては，短期間に動脈瘤の増大を認めることが多い点 であり ${ }^{225) 7) 9)}$, 今回の症例でもこのような例を 2 例経験し ている $($ Case 5,7) 。この2例の初回血管撮影では, 動脈瘤 は内頸動脈のわずかな隆起とし描出されるだけであった.
したがって典型的なクモ膜下出血で動脈瘤が発見できない 場合, 随伴する狭窄や内腔不整などの動脈硬化像の所見と あわせて, 本動脈瘤の存在を念頭において慎重に血管撮影 像を読影することが大切である ${ }^{10)}$.

本動脈瘤の他の臨床的特徴として, 動脈瘤頸部をも含め た壁の脆弱性のため術中破裂が起きやすく，破裂した場合， 頸部から千切れるように破裂し, 術中止血困難に陥ること が多いこと 2)4) -6)8) -11) が挙げられている.われわれの例 でも3例が術中に破裂し，1例は clipping 可能であったが， ほか 2 例では, 内頸動脈の綘合による血管形成を必要とし た。

本動脈瘤の治療については, 動脈瘤自身が破裂しやすく, 破裂すると止血困難に陥ることから，手術手技に関して 様々な方法が提唱されている. 本動脈瘤に対し, 安易な頸 部の剥離と, clippingは危険を伴い, 厳に慎まなければな らない. 動脈瘤の clippingに際して, 内頸動脈を一部狭窄 させるように頸部を形成し, 内頸動脈と平行な方向に clippingすること, また術後 clipの脇から動脈瘤が再拡大 したり, 出血することから, clipping と共に十分な wrappingを加えることが, 過去の報告より本動脈瘤処置にあ

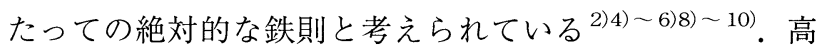

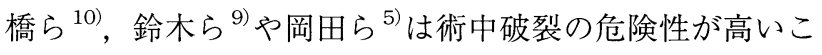
とから, 開頭前に頸部内頸動脈を確保し, 動脈瘤近傍の剥 離操作時には内頸動脈の血流遮断を行う必要があるとして いる.

その他, 過去の報告ではblister typeの動脈瘤の場合 wrappingした上から clippingしたり ${ }^{3)}$, 内頸動脈の trappingに備えてEC-IC bypassを用意したり ${ }^{2) 5)}$, Sundt clip 
を用いて内頸動脈の全周を被う ${ }^{25)}$ などがある。われわれ の例でも，多くは内頸動脈を一部狭窄させるように頸部を 形成し, 内頸動脈と平行な方向に clippingし, 十分な wrappingを加えることにより，本動脈瘤を処理すること は可能であった。また，このように動脈瘤を処理した例で は, 動脈瘤の再拡大や再破裂なく転帰もおおむね良好であ った。

本動脈瘤がclipping 可能な場合, 上記のいずれかの方法 を用いて行うのが原則であるが，術中最も術者を悩ませる 問題は，本動脈瘤が破裂した場合である。破裂した場合， 動脈瘤ごと千切れて内頸動脈がlaceretionする場合が多く, 過去の報告では, 内頸動脈の壁を一部凝固して頸部を形成 したうえでclippingする方法が報告されている。今回血管 形成を行った2例では, lacerationの幅が広く, clippingに よる血管形成は不可能と判断し, laceration部位を縫合し た。この 2 例は術後血管撮影ないし解剖所見にて angioplasty 部分の狭窄は認めるものの patencyを認めた。2例 とも術前重症度分類では, Grade V と悪いのと, 血管形成 時の血行遮断による血行不全も加わったため転帰不良の経 過をとったと考えられる。

本動脈瘤を処置するうえで最も重要な問題は, 本動脈瘤 に対する慎重な剥離操作にもかかわらず術中破裂を起こす 可能性や動脈瘤壁の脆弱部分の範囲を術前血管撮影などで 予見できるかどうかである。術中破裂の術前の予見に関し ては, Case 6のごとく動脈瘤の domeの部分が不規則で, CT上動脈瘤付近の脳槽に血腫が存在するものは術中破裂 の可能性が大きいが, saccular typeになっているものは, 予見不可能である．また，動脈壁の脆弱部位の範囲につい ては，術前血管撮影での予見は困難と考えられる。したが って血管形成の可否は, 術中に観察される動脈壁の脆弱部 分の範囲によって判断せざるを得ない. 術中, 動脈壁の脆 弱部分が正常な動脈壁より幅が広い場合, clipによる血管 形成は, 内頸動脈の極度の狭窄と血行不全を引続き起こし, 患者の転帰に大きく影響を及ぼす結果となる。このような 場合, 動脈瘤と ICを一緒に全周にわたってBemsheetなど で wrapping し，その上から IC に平行に parallel clipping するか, または high flow shunt を行い本動脈瘤を trapping する必要があると考えられる。

\section{結語}

1. 過去 5 年間に 7 例の頭蓋内内頸動脈前壁動脈瘤を経験
し，治療上の問題点について検討した.

2. 本動脈瘤では, 慎重な剥離操作と頸部付近の動脈璧の 脆弱部位を含むようにclippingすることにより，処理 可能な場合が多いが， regrowthを予防するために動 脈瘤周囲の wrapping が必要であった。

3. 動脈瘤頸部が laceration した場合, 内頸動脈の血管形 成と周囲をwrapping することが必要であったが，血 管形成はきわめて困難で，転帰も不良であった。

4. 術前血管撮影等で, 術中破裂や動脈壁の脆弱部分の範 囲を予見することは困難であるため, 術中に動脈壁の 脆弱部分の範囲により血管形成の可否が決まる。動脈 壁の脆弱部位が正常血管より幅が広い場合, 動脈瘤と ICを一緒に全周にわたって Bemsheetなどで wrappingし，その上から IC に平行に parallel clipping す るか, または high flow shuntを行い本動脈瘤を trapping する必要があると考えられた。

\section{文献}

1) 金子満雄, 田中敬生, 村木正明, ほか: 小型immature berry aneurysmに対する診断と外科治療. 第 13 回脳卒中の 外科研究会講演集, 1984, pp 255-259

2) 小林茂昭, 中川福夫, 京島和彦, ほか: 内頸動脈背側動脈 瘤の特殊性と手術手技上の問題点. 第 12 回脳卒中の外科研 究会講演集, 1983, pp 56-60

3 ）加藤庸子, 佐野公俊, 笹間 睦, ほか: 壁の薄い動脈瘤の 手術とその考察．脳卒中の外科 19: 615-618, 1991

4) Nakagawa F, Kobayashi S, Takemae T, et al: Aneurysms protruding from the dorsal wall of the internal carotid artery. J Neurosurg 65: 303-308, 1986

5 ) 岡田純一郎, 横田 仁, 酒井龍雄, ほか: 内頸動脈 cisternal portionの blister aneurysmの治療. 第 13 回脳卒中の外 科研究会講演集, 1984, pp 255-259

6) 斎木 厳, 西沢義彦, 鳴海新, ほか: 粒状脳動脈瘤の外 科治療に関する検討. 第 13 回脳卒中の外科研究会講演集, 1984, pp 245-249

7 ) 佐藤 章, 中村 弘, 小滝繁樹, ほか: 内頸動脈の high risk動脈瘤; dorsal IC aneurysmについて. 脳卒中の外科 21: $467-472,1993$

8) 重田裕行, 小林茂昭, 京島和彦, ほか: 内頸動脈背側型動 脈瘤の臨床的検討. 脳卒中の外科 19: 125-129, 1991

9）鈴木健一, 森山 貴, 鳴瀬 修, ほか: 術後比較的短期間 に再発，増大した内頸動脈瘤例。脳卒中の外科 15: 13-16, 1987

10）高橋 明, 鈴木二郎, 藤原 悟: 内頸動脈 $\mathrm{C}_{2}$ 部チマメ状動 脈瘤の手術. 脳卒中の外科 16: $72-71,1988$

11) Yaşargil MG: Clinical considerations, surgery of the intracranial aneurysms and results. In: Microneurosurgery, Vol. 2, George Thieme Verlag, Stuttgart/New York, 1984, pp 33-123 